Portland State University

PDXScholar

\title{
Attachment, Social Support Satisfaction, and Well- Being During Life Transition in Emerging Adulthood
}

Joel A. Lane

Portland State University, lanejoel@pdx.edu

Robert S. Fink

Oakland University

Follow this and additional works at: https://pdxscholar.library.pdx.edu/coun_fac

Part of the Counseling Psychology Commons, and the Student Counseling and Personnel Services Commons

Let us know how access to this document benefits you.

\section{Citation Details}

Lane, Joel A. and Fink, Robert S., "Attachment, Social Support Satisfaction, and Well-Being During Life Transition in Emerging Adulthood" (2015). Counselor Education Faculty Publications and Presentations. 44.

https://pdxscholar.library.pdx.edu/coun_fac/44

This Post-Print is brought to you for free and open access. It has been accepted for inclusion in Counselor Education Faculty Publications and Presentations by an authorized administrator of PDXScholar. Please contact us if we can make this document more accessible: pdxscholar@pdx.edu. 
Attachment, Social Support Satisfaction, and Well-Being During Life Transition in Emerging Adulthood Joel A. Lane

Oakland University

Author Note:

Joel A. Lane, Department of Counseling, Oakland University.

Joel A. Lane is now at the Department of Counselor Education, Portland State University. This research was previously published as a doctoral dissertation. This research was supported in part by a grant from the Association of Adult Development and Aging. The author wishes to acknowledge Drs. Robert Fink, Todd W. Leibert, Stephanie A. Crockett, Mary Beth Snyder, Julia Smith, and Russell Miars for their contributions in the development of the project and/or feedback regarding drafts of the manuscript.

Correspondence concerning this article should be addressed to Joel A. Lane, Department of Counselor Education, Graduate School of Education, Portland State University, P. O. Box 751, 615 SW Harrison, Room 504A, Portland, OR 97207. E-mail: lanejoel@pdx.edu 


\begin{abstract}
The present study was designed to investigate the relations among attachment, social support satisfaction, and well-being in a cross-sectional sample of emerging adults $(N=213)$ experiencing one or more normative life transitions. The sample represented a range of educational and vocational backgrounds. The primary hypotheses were that social support satisfaction would mediate the associations between each attachment dimension and well-being. A corresponding theoretical model was tested using structural equation modeling. The model provided an excellent fit to the sample data. Social support satisfaction mediated the association between attachment anxiety and well-being, but not the association between attachment avoidance and well-being. That is, attachment anxiety was indirectly associated with well-being through social support satisfaction, while attachment avoidance was directly associated with well-being. Alternative model testing provided mixed support for the variable ordering in the theoretical model. Implications are provided for future research and for counseling emerging adult clients experiencing transition.
\end{abstract}

Keywords: emerging adulthood, attachment, social support satisfaction, well-being 
Attachment, Social Support Satisfaction, and Well-Being During Life Transition in Emerging

\section{Adulthood}

Emerging adulthood is a stage of life occurring between the ages of 18 and 29 among individuals in industrialized nations. During the emerging adult years, numerous significant life transitions occur (Arnett, 2004). For example, it is normative for emerging adults to graduate from high school, leave home, enter (and subsequently graduate from) college, enter the workforce, enter into long-term romantic relationships, and start a family. Each of these transitions involve changes in social networks, familial support, and autonomy (Cohen, Kasen, Chen, Hartmark, \& Gordon, 2003). Such transitional changes add to the instability and uncertainty characteristic of this stage of life (Arnett, 2004). Moreover, emerging adults engage in an extended identity exploration process with respect to previous generations of 18- to 29year-olds, often delaying enduring decisions concerning career and family. The convergence of each of these factors results in a complex transition process with implications for well-being and psychological functioning (Lane, 2015; Lee \& Gramotnev, 2007).

The present study conceptualizes life transitions in emerging adulthood as critical periods for well-being, during which many are able to thrive while others experience increased distress and reduced well-being. Such a conceptualization has been supported in research concerning graduating from high school (Gore \& Aseltine, 2003), entering (Kenny \& Donaldson, 1991) and leaving (Lane, in press) college, and adjusting to professional life (Polach, 2004). The distress created by emerging adult life transitions is especially problematic given that this age group is prone to risky and impulsive coping behaviors including binge drinking, drug use, and risky sexual behaviors (Bachman, Johnston, O’Malley, \& Schulenberg, 1996). Moreover, the emerging adult years are a period of elevated psychiatric risk, as the average age of onset for 
most depressive, anxiety, psychotic, and personality disorders occurs during the 20's (Ingram \& Gallagher, 2010). These challenges appear to be especially pronounced in vulnerable populations that are less likely to attend college, including those from low socioeconomic backgrounds and non-white individuals (e.g., Gore \& Aseltine, 2003). In essence, there are many psychological challenges in emerging adulthood, for which transitional distress seems to pose as a catalyst.

Because these problems may be exacerbated by life transition, it is imperative to better understand factors that promote mental health and the maintenance of well-being during emerging adulthood. Such has been the aim of the aforementioned transition studies. Many of these studies have identified attachment security (e.g., Kenny \& Donaldson, 1991) or social support (Polach, 2004) as being important protective factors for emerging adults experiencing specific transitions, which is logical given that both constructs are theorized to be salient during times of distress. The aim of the present study, then, was to explore the roles of attachment and social support satisfaction in facilitating well-being during emerging adult life transitions.

\section{Attachment}

According to attachment theory, the early relationships we develop with our caregivers inform our attitudes toward help-seeking and new learning in times of distress across the lifespan (Bowlby, 1969/1982). The relative quality of these caregiver relationships results in internalized attachment representations regarding the efficacy of self and others. That is, children whose caregivers are consistently responsive to their needs are more likely to trust that their future needs will be met, helping them feel secure in their own capabilities and in the helpfulness of others. These attachment representations influence and are influenced by subsequent interpersonal experiences throughout the lifespan. In adulthood, attachment representations are best understood as orthogonal dimensions of attachment anxiety (i.e., the relative security of 
one's self-representations) and attachment avoidance (i.e., the relative security of one's otherrepresentations; Brennan, Clark, \& Shaver, 1998). Elevated attachment anxiety could contribute to a belief that one is incapable of successfully handling distressing situations, perpetuating interpersonal dependence. Elevated attachment avoidance could contribute to a belief that other cannot be trusted in times of distress, perpetuating interpersonal isolation.

The relevance of attachment in the present study is demonstrated through numerous emerging adult studies. In a longitudinal sample of emerging adult males in Israel, attachment security predicted positive coping strategies and the capacity for intimacy during the transition out of high school and into compulsory military service (Scharf, Mayseless, \& Kivenson-Baron, 2004). In cross-sectional samples in the United States, attachment security has also predicted psychological health and transition concerns among college freshmen (Kenny \& Donaldson, 1991) and seniors (Lane, in press), as well as depressive symptoms among older emerging adults (Kenny \& Sirin, 2006). In longitudinal research with United States samples, the quality of parental relationships was associated with well-being trajectories during the transitions out of high school (Gore \& Aseltine, 2003) and into professional life (Buhl, 2007).

\section{Social Support Satisfaction}

Like attachment, the construct of social support has both conceptual and empirical applicability to the topic of life transition in emerging adulthood. Social support refers to the perceived quality of social relationships with regard to providing various forms of assistance both tangible (e.g., monetary) and intangible (e.g., emotional) — during times of need (Sarason et al., 1991). Empirical evidence suggests two mechanisms by which social support can be beneficial: (a) its capacity to mitigate stress during stressful situations (e.g., Ditzen et al., 2008), and (b) its contribution to well-being and physical health (e.g., Cohen, 2004). Therefore, social 
support has implications for psychological functioning in both short- and long-term contexts.

In the present study, social support was conceptualized as satisfaction with emotional forms of social support. Recent research has strongly suggested the importance of this and other types of perceived social support during emerging adulthood. Qualitatively, emerging adults have identified changes in perceived support after entering post-college employment as psychologically challenging (Polach, 2004), and they have described the salience of social support to post-college adjustment and career decision-making (Mortimer, Zimmer-Gembeck, Holmes, \& Shanahan, 2002). Longitudinally, changes in perceived support throughout emerging adulthood correlate with increases in subjective well-being (Galambos, Barker, \& Krahn, 2006).

\section{Attachment and Social Support Satisfaction}

Because attachment representations are theorized to influence patterns of interpersonal interaction, it follows that attachment would impact the perceived quality of one's social support network. A wealth of research has demonstrated the interrelatedness of these constructs and their helpfulness to mental health and functioning (e.g., Ditzen et al., 2008; Vogel \& Wei, 2005). The most frequently identified pattern of relations among these variables involves social support as a mediator of the impact of attachment security on various psychological outcomes (e.g., Vogel \& Wei, 2005). In this conceptualization, attachment anxiety and attachment avoidance both contribute to decreased satisfaction with social support. In the case of attachment anxiety, negative representations of self diminish support satisfaction via a heightened sensitivity to the potential unavailability of others in times of need. In the case of attachment avoidance, negative representations of others diminish support satisfaction due to a desire for interpersonal distance. These disruptions would contribute to diminished psychological outcomes by preventing the aforementioned benefits derived from satisfying social relationships. 
However, a relative dearth of literature in this area exists with a specific focus on emerging adulthood. This gap is noteworthy given the transfer of attachment relationships and changes in social functioning that occur in the transition from adolescence to adulthood. Historically, individuals in later adolescence and emerging adulthood increasingly rely on peers and romantic partners for many attachment-related needs, while parents and caregivers are more likely to be called upon in times of significant need (Fraley \& Davis, 1997). Recent societal trends, however, have resulted in increased complexity of these relationships (Arnett, 2004). Such trends include expanded access to sources of social support due to the proliferation of social media (Manago, Taylor, \& Greenfield, 2012), increases in one's number of serious romantic partners due to waiting longer to settle down (Arnett, 2004), and increased parental involvement in the emerging adult years (Padilla-Walker \& Nelson, 2012). It is, therefore, conceivable that the relatedness of attachment and social support satisfaction among emerging adults is unique compared to other age groups. Thus, the nature of relatedness among these constructs for emerging adults has yet to be confirmed. Given that attachment strategies and social support are most useful in times of distress, it would be useful to examine these relations in a group of emerging adults experiencing various life transitions. That is, the ensuing transition-related distress would likely provide a more accurate reflection of how emerging adults utilize interpersonal relationships to navigate life changes and maintain well-being.

\section{Well-Being}

Historically, the scope of most psychological research has been dysfunction and negative affective states (Lent, 2004). Conversely, well-being research involves factors that are predictive of individuals leading happy, fulfilling, and productive lives. The focus is not the absence of negative symptoms, but rather, the presence of positive characteristics and affect. However, 
critiques of well-being research have highlighted a lack of theory-grounded conceptualizations (Ryff, 1989) and persistent absence of justification for choosing measurement constructs (Lent, 2004). Some authors differentiate psychological well-being (PWB) from subjective well-being (SWB), with the former representing an individual's overall mental health and psychological functioning (Ryff, 1989) and the latter pertaining to life satisfaction and the balance between positive and negative affect (Lent, 2004). Accordingly, examining both PWB and SWB in the present study would provide a more complete understanding of well-being as a whole.

\section{Present Study}

While the literature examining the impact of attachment dimensions and/or social support on various aspects of functioning is robust, several key limitations remain. First, attachment and social support research has tended to focus on negative symptoms, such as psychological distress (e.g., Mallinckrodt \& Wei, 2005; Vogel \& Wei, 2005), stress (e.g., Ditzen et al., 2008), or depression (Kenny \& Sirin, 2006). Much less emphasis has been placed on how these constructs promote positive qualities, resulting in a knowledge gap regarding the impact of attachment and social support on well-being. Second, most emerging adult researchers to date have examined attachment or social support, not both. While it is true that attachment and social support researchers often utilize college samples — and in so doing, are predominantly examining emerging adults — they generally do so in an attempt to generalize findings to the greater adult population, and they are only examining a specific subset of emerging adults (i.e., those who attend college). Thus, it could be argued that little is known about the direct and indirect relatedness of attachment, social support, and well-being for emerging adulthood in general, which includes current and former college students, as well as those not enrolled in college. Finally, the roles of attachment and social support for individuals experiencing life transition 
have not been explored in existing research.

The present study was designed to examine the extent to which emerging adults experiencing normative life transitions rely on attachment and social support satisfaction to maintain well-being. The presence of life transitions was chosen as a necessary condition for participation because of the aforementioned evidence that transitions in emerging adulthood potentiate psychological distress (e.g., Lee \& Gramotnev, 2007), which presumably would activate attachment and social support strategies (Brennan et al., 1998). Specifically, based on the aforementioned theoretical and empirical works related to these constructs, the primary study hypotheses were that social support satisfaction would mediate the associations between 1) attachment anxiety and well-being, and 2) attachment avoidance and well-being. In other words, given that life transitions are potentially distressing for emerging adults, attachment anxiety would be negatively associated with social support satisfaction due to an increased sensitivity to the potential unavailability of others in times of need, while attachment avoidance would be negatively associated with social support due to a desire for interpersonal isolation in times of need (Lopez \& Brennan, 2000). Through each of these associations with social support satisfaction, attachment anxiety and avoidance would also be indirectly associated with wellbeing. It was further hypothesized that the direct effect of each attachment dimension on wellbeing would be nonsignificant after accounting for the effect of social support satisfaction. These hypotheses are depicted in Figure 1 and were tested using structural equation modeling (SEM).

\section{Method}

\section{Participants and Procedure}

The present study utilized a cross-sectional survey design. The survey was electronic and consisted of 85 items, beginning with a demographic questionnaire. The demographic questions 
elicited information pertaining to participant age and cultural characteristics, and it contained a checklist of possible transitions (e.g., first year in college) the participant may be experiencing.

Participants were recruited through various means in an effort to attain a more representative sample of emerging adults than previous studies with college student samples. Participants enrolled in higher education programs were recruited during class sessions. Recruitment messages were also sent to recent college graduates affiliated with a university alumni association. To obtain participants outside of traditional higher education, emerging adults affiliated with a large cosmetology training program were recruited. The rationale for using this training program was that it offered a large pool of young adults who, presumably, were not enrolled in traditional higher education. Other studies attempting to recruit non-college attenders have also relied on professional training programs (e.g., Seiffge-Krenke, Persike, \& Luyckx, 2013). Finally, snowball sampling was utilized, in which participants were encouraged to invite 3-5 acquaintances to participate. Prospective participants were given a link to the electronic survey via email. Those who completed the survey were entered into a prize drawing for one of three $\$ 50$ online gift cards. In all, 213 completed surveys were submitted that met the study's inclusion criteria. This sample size was ideal given that moderately complex theoretical models require samples of at least 200 participants (Marsh, Balla, \& McDonald, 1988). Of the 213 participants, $63(29.6 \%)$ were recruited from the alumni emails, 49 (23.0\%) were recruited from college classes, $36(16.9 \%)$ were recruited from the cosmetology training program, and the rest $(65,30.5 \%)$ were recruited from snowball sampling. ANOVA analyses were conducted to explore group differences between these recruitment strategies. To account for familywise error rate, Bonferroni correction was used so that differences were only considered significant when $p$ $<.05 / 4=.013$. None of the variables differed significantly across the recruitment groups. 
The targeted population for this study was emerging adults experiencing one or more normative life transitions. Participants were eligible to participate if they (a) were between the ages of 18 and 29, and (b) reported that they were engaged in a life transition consistent with emerging adulthood. A list of transitions was provided, and participants could also indicate additional transitions they were experiencing. The most prominently reported transition was the first year of career life $(n=65,30.5 \%)$. Other reported transitions included the first year after high school graduation $(n=21,9.9 \%)$, the first academic year of college $(n=29,13.6 \%)$, the final semester of a higher education program $(n=37,17.4 \%)$, the first six months after graduating from college $(n=50,23.5 \%)$, the first semester of a graduate-level educational program $(n=35,16.4 \%)$, the first year of marriage $(n=24,11.3 \%)$, and the first year of parenthood $(n=8,3.8 \%)$. Ninety-eight participants $(46 \%)$ reported more than one current transition. A series of independent samples t-tests revealed no significant study variable differences between participants endorsing one vs. multiple transitions (non-mutually exclusive transitions [e.g., graduating high school and beginning college] were coded as a single transition), with $F$ values ranging from $F[2,210]=.122, p=.73$ (with life satisfaction as the outcome variable) to $F[2,210]=2.33, p=.13$ (with negative affect as the outcome variable).

The mean age of the sample was 22.94 years old (Range $=18-29, S D=2.65)$. The majority of the participants $(n=154,72.3 \%)$ identified as female (all other participants identified as male despite the availability of "other" as an answer choice). Most participants ( $n=177$, 83.1\%) identified as non-Latino White, though 7.0\% identified as African American, 2.8\% as Asian American, 2.8\% as Hispanic/Latino, 2.8\% as Arab American, and 1.4\% as multiracial. Participants also reported their educational attainment, post-high school educational trajectories, and post-high school decisions regarding leaving home. The most frequently selected educational 
answer choice indicated completion of an undergraduate degree $(n=78,36.6 \%)$, followed by present undergraduate enrollment $(n=72,33.8 \%)$, present graduate school enrollment $(n=43$, $20.2 \%)$ and no current college enrollment or degree $(n=20,9.4 \%)$. It should be noted, however, that several of the participants from the cosmetology training program indicated present college enrollment, as these numbers do not accurately reflect the percentages of participants from each recruitment strategy. The majority entered college full-time after high school $(n=186,87.3 \%)$ and left home within six months of graduating from high school $(n=111,52.1 \%)$.

\section{Instruments}

Attachment dimensions. The Experiences in Close Relationships Scale- Short Form (ECR-S; Wei, Russell, Mallinckrodt, \& Vogel, 2007) is a 12-item self-report measure designed to assess adult attachment. It is derived from the original 36-item Experiences in Close Relationships Scale (Brennan et al., 1998). The items comprising the ECR-S utilize a seven-point scale $(1=$ strongly disagree, 7 = strongly agree $)$ in assessing participant agreement with various statements related to the dimensions of attachment anxiety (e.g., "I worry that romantic partners won't care about me as much as I care about them") and attachment avoidance (e.g., "I am nervous when partners get too close to me"), respectively. The item ratings for each subscale are summed, with higher total scores indicating greater attachment anxiety and attachment avoidance, respectively. Using multiple large college student samples, the authors (Wei et al., 2007) demonstrated ECR-S factor structure through cross-validated factor analyses, while validity was supported through cross-validated correlations with various constructs indicative of attachment insecurity, including depression, loneliness, and distress, as well as emotional reactivity (for attachment anxiety) and emotional cutoff (for attachment avoidance). The authors also reported internal consistencies ranging from .77 to .86 for the anxiety subscale and .78 to .88 
for the avoidance subscale. In the present sample, internal consistencies were comparable: $\alpha=$ .75 and $\alpha=.85$, respectively.

Social support satisfaction. The Social Support Questionnaire (SSQ6; Sarason, Sarason, Shearin, \& Pierce, 1987) is a six-item self-report measure used to assess satisfaction with available social supports. Each of the SSQ6 items ask participants to list all of the individuals who could be relied upon for help or support in a given scenario (e.g., "Whom can you count on to distract you from your worries when you feel under stress?"), and then to rate their overall satisfaction with the support they receive on a six-point scale, with lower scores indicating higher satisfaction $(1=$ very satisfied, 6 = very dissatisfied $)$. In the present study, only the satisfaction ratings were utilized in the data analysis. Responses were reverse scored and summed so that higher values were indicative of greater satisfaction. The SSQ6 authors used a large college student sample to provide evidence for validity through correlations between the SSQ6 satisfaction scale and social competence, loneliness, hostility, anxiety, and depression. In the same study, the authors reported high SSQ6 satisfaction scale internal consistency $(\alpha=.93)$ and test-retest reliability after a 3-4 week interval (.85). Internal consistency in the present sample was .90 .

Well-being. Because the conceptualization of well-being in the present study included both SWB and PWB, instruments were selected that measured dimensions of each of these constructs. SWB is often conceptualized to include life satisfaction, a high degree of positive affect, and a low degree of negative affect (Lent, 2004). Though many conceptualizations of PWB exist, one conceptualization (Ryff, 1989) combines common factors inherent in multiple theories of healthy psychological functioning. These conceptualizations guided the selection of the following well-being indices. 
Satisfaction with Life Scale (SWLS). The SWLS (Diener, Emmons, Larsen, \& Griffin, 1985 ) is a 5-item self-report assessment of life satisfaction (e.g., "In most ways my life is close to my ideal"). Participants rate their agreement with each item on a 7-point scale $(1=$ strongly disagree, 7 = strongly agree $)$. The scores for each item are summed, resulting in a total score range of 5-35. The authors used a college student sample to support validity through correlations with positive affect, self-esteem, neuroticism, and other SWB indices. They also reported an alpha coefficient of .87 and a 2-month test-retest reliability coefficient of .82. Internal consistency in the present sample was .87 .

Positive and Negative Affect Schedule (PANAS). The PANAS (Watson, Clark, \& Tellegen, 1988) is a 20-item self-report measure used to assess positive and negative affect. Each PANAS item is comprised of a single emotion word (e.g., "guilty"), and the participant is asked to rate on a 5-point scale $(1=$ very slightly or not at all, $5=$ very much $)$ how frequently they experienced that emotion during the past month. Of the 20 items, 10 each correspond to positive and negative affect, resulting in a possible score range of 10-50 for each subscale, with higher scores indicating higher levels of positive and negative affect, respectively. Using separate college student and adult samples, the authors demonstrated convergent and discriminant validity using factor analysis and non-significant correlations between the two subscales. The college student sample was used to support external validity through correlations with various measures of distress and psychopathology. The authors reported internal consistencies across the college student and adult samples ranging from .86 to .90 for positive affect and .84 to .87 for negative affect. The present sample internal consistencies were .87 and .85 , respectively.

Ryff Scales of Psychological Well-Being (RSPWB). The RSPWB (Ryff, 1989) is a selfreport measure designed to assess PWB. Its six subscales were developed in line with various 
psychological theories of healthy functioning (e.g., self actualization). The six subscales consist of autonomy, environmental mastery, personal growth, positive relations with others, purpose in life, and self-acceptance. The original RSPWB contained 120 items; the version used in the present study contained 42 items (Springer \& Hauser, 2006), seven items per subscale. Each of the items consists of self-statements (e.g., "I have the sense that I have developed a lot as a person over time") for which participants rate their agreement using a 6-point scale (1 = agree strongly, 6 = disagree strongly). Items for each subscale were reverse scored and summed so that higher scores were indicative of higher degrees of each subscale. The author (Ryff, 1989) used separate young adult, middle aged, and older adult samples to examine RSPWB reliability and validity. Test-retest reliability over a 6-week period ranged from .81 to .88 . Multivariate and mean-level analyses of the full sample supported the RSPWB factor structure, and evidence of external validity was provided through correlations with other measures of psychological health using the full sample. Internal consistencies in the present sample ranged from .74 to .84.

\section{Data Analysis}

The SEM analyses were executed using Mplus Version 7.3 (Muthén \& Muthén, 19982012). Missing data were screened for potential non-randomness using Little's Missing Completely at Random (MCAR) test (Little, 1988). Twenty four of the 85 survey items (28.2\%) contained one or more missing responses; no item contained more than three missing responses, resulting in a completion rate of at least $98.6 \%$ for all items. Results of the MCAR test were not significant: $\chi^{2}(1510)=1592.64, p=.07$, indicating that data were missing completely at random. Accordingly, SEM analyses were conducted using full information maximum likelihood (FIML) estimation (Schlomer, Bauman, \& Card, 2010). Model fit was assessed using several fit indices as recommended by $\mathrm{Hu} \&$ Bentler (1999). The chi-square goodness of fit test $(\chi 2)$ was 
used to examine model fit, with smaller $\chi^{2}$ values indicating better fit. However, preliminary analyses provided evidence for multivariate nonnormality; consequently, the Satorra-Bentler corrected scaled $\chi 2$ (SB- $\chi 2$; Satorra $\&$ Bentler, 2001) was used in all subsequent analyses, and all difference tests $\left(\Delta \chi^{2}\right)$ were calculated following the method outlined by Satorra and Bentler (2001). Other fit indices used included the (a) root mean square error of approximation (RMSEA), for which values of .06 and smaller indicate excellent model fit; (b) comparative fit index (CFI), which should exceed .95; and (c) standardized root-mean-square-residual (SRMR), for which values smaller than .08 indicate excellent fit (Hu \& Bentler, 1999). In addition to the RMSEA value, RMSEA 90\% confidence intervals (CI) were also provided.

The significance of the indirect effects was tested using bias-corrected bootstrapping (Shrout \& Bolger, 2002). This method evaluates significance by generating 95\% confidence intervals of the indirect effects through repeatedly sampling the data set to test the model. The analysis was set to execute 10,000 bootstrapped samples (Mallinckrodt, Abraham, Wei, \& Russell, 2006). Shrout and Bolger (2002) recommended reporting the $95 \%$ confidence intervals when employing bias-corrected bootstrap analyses since the intervals provide the basis for statistical significance. This method of examining indirect effects offers greater statistical power than other methods (Mallinckrodt et al., 2006; Shrout \& Bolger, 2002).

\section{Results}

\section{Confirmatory Factor Analysis of the Measurement Model}

Analysis of the theoretical model utilized a two-step approach (Anderson \& Gerbing, 1988). The first step involved testing the measurement model using confirmatory factor analysis. Item parcels were created for constructs measured by a single measurement variable (i.e., attachment anxiety, attachment avoidance, social support satisfaction; Russell, Kahn, Spoth, \& 
Altmaier, 1998). This was done so that each latent variable would contain multiple indicators.

The parcels were created by first rank-ordering items for each variable on the basis of the magnitude of their item-total correlations. Next, items were divided into three-item parcels so that the sum of their item-total correlations were roughly equivalent. Thus, the latent variables of attachment anxiety, attachment avoidance, and social support satisfaction were each estimated by two sets of three-item parcels, while the well-being latent variable was estimated nine observed variables: life satisfaction, positive affect, negative affect (which was hypothesized to load in the opposite direction than the other observed variables), and each of the six RSPWB subscales.

Results indicated an adequate, but not excellent, data fit: $\mathrm{SB}-\chi 2(84, N=213)=189.24, p$ $=.00 ; \mathrm{RMSEA}=.08(\mathrm{CI}=.06$ to .09$) ; \mathrm{CFI}=.93 ; \mathrm{SRMR}=.06$. However, all observed variables were statistically significant and loaded onto their respective latent variables in the hypothesized directions. Several steps were taken to improve model fit. Because the latent well-being variable was comprised of constructs of both SWB and PWB, a nested model was tested with separate latent variables for SWB (using life satisfaction, positive affect, and negative affect as observed variables) and PWB (using the six RSPWB subscales as observed variables). Again, this model provided an adequate, but not excellent, data fit: $\mathrm{SB}-\chi 2(80, N=213)=180.49, p=.00 ;$ RMSEA $=.08(\mathrm{CI}=.06$ to .09$) ; \mathrm{CFI}=.93 ; \mathrm{SRMR}=.06$. This model did not provide a significantly different fit compared to the original measurement model according to the scaled difference test: $\Delta \chi^{2}(4)=8.80, p=.07$. Subsequent modifications, therefore, occurred using the original measurement model based on the parsimony principle. First, the RSPWB autonomy and personal growth subscales were removed because their error variances correlated with several of the other RSPWB subscales. Some authors (e.g., Lent, 2004) have argued that certain dimensions of PWB contribute to one another, which would both explain the correlated error and suggest that 
removing the autonomy and personal growth variables would not compromise the well-being latent variable. The resulting measurement model provided an excellent fit to the data: SB- $\chi 2$ $(59, N=213)=101.90, p=.00 ; \mathrm{RMSEA}=.06(\mathrm{CI}=.04$ to .07$) ; \mathrm{CFI}=.97 ; \mathrm{SRMR}=.05$. As a final step, the remaining well-being observed variables were again separated into SWB and PWB variables, this time with PWB containing the remaining four RSPWB subscales as observed variables. This model provided a good fit to the data: $\operatorname{SB}-\chi 2(55, N=213)=94.69, p=.00$; $\mathrm{RMSEA}=.06(\mathrm{CI}=.04$ to .07$) ; \mathrm{CFI}=.97 ; \mathrm{SRMR}=.05 ;$ however, it was not significantly different from the modified single latent well-being variable model: $\Delta \chi 2(4)=7.18, p=.13$. Thus, the modified measurement model incorporating a single well-being variable was deemed the best-fitting model on the basis of the parsimony principle. The factor loadings are displayed in Table 1. In this modified measurement model, well-being was estimated by seven factors: life satisfaction, positive affect, negative affect, self-acceptance, positive relations with others, purpose in life, and environmental mastery. Means, standard deviations, and correlations for the instrument scales are shown in Table 2.

\section{Structural Model Analysis}

To examine the efficacy of the theoretical model, a series of nested models were tested. First, a fully recursive model (Model A) was tested by allowing all paths in Figure 1 to be free for estimation. This model provided an excellent fit to the data: $\operatorname{SB}-\chi 2(59, N=213)=101.90, p$ $=.00 ; \mathrm{RMSEA}=.06(\mathrm{CI}=.04$ to .07$) ; \mathrm{CFI}=.97 ; \mathrm{SRMR}=.05 . \mathrm{Next}$, the fully mediated theoretical model (Model B) was tested in which the paths connecting the attachment variables to well-being were fixed to 0 . This model provided an adequate fit to the data: $\operatorname{SB}-\chi 2(61, N=213)$ $=117.26, p=.00 ; \mathrm{RMSEA}=.07(\mathrm{CI}=.05$ to .08$) ; \mathrm{CFI}=.96 ; \mathrm{SRMR}=.08$. The scaled difference was significant: $\Delta \chi 2(2)=28.15, p=.00$, indicating that the theoretical model 
provided a significantly worse fit than the recursive model. Thus, Model A was deemed the best fitting model. The Model A path estimates are provided in Figure 2. In all, the model accounted for $24 \%$ of the variance in social support satisfaction and $43 \%$ of the variance in well-being.

\section{Statistical Significance of Indirect Effects}

Next, the indirect effects were examined using bias-corrected bootstrapping. Indirect effects were considered significant when the 95\% CI did not include zero (Mallinckrodt et al., 2006; Shrout \& Bolger, 2002). As predicted, the indirect effect involving attachment anxiety as the predictor was statistically significant $(\beta=-.21, B=-.45,95 \% \mathrm{CI}=-.87$ to $-.24, p<.001)$, indicating that social support satisfaction significantly mediated the association between attachment anxiety and well-being. Thus, Hypothesis 1 was supported. However, the indirect effect involving attachment avoidance as a predictor was not significant $(\beta=-.05, B=-.10,95 \%$ $\mathrm{CI}=-.28$ to $.03, p>.05)$, indicating that social support satisfaction did not mediate the association between attachment avoidance and well-being. Therefore, Hypothesis 2 was not supported. It is useful to note that the direct effect of attachment anxiety predicting well-being was not significant $(\beta=-.16, p>.05)$, while the direct effect of attachment avoidance predicting well-being was significant $(\beta=-.17, p<.05)$. In tandem with the indirect effects, the findings suggest social support satisfaction fully mediated the effect of attachment anxiety on well-being, while it had no effect on the association between attachment avoidance and well-being.

\section{Alternative Model Testing}

Due to the cross-sectional nature of the data, several alternative models were developed and tested. These alternative models comprised different relations among the study variables. Demonstrating that these alternative models provided inferior fits to the data would further support the present theoretical model. In the first alternative model (Model C), the order of the 
attachment dimensions and social support satisfaction were reversed. This alternative model was used to test the possibility that satisfying social relationships would be associated with increased attachment security during emerging adult life transitions, which in turn would be associated with increased well-being. This model provided an adequate, but not excellent, fit to the data: $\mathrm{SB}-\chi^{2}(60, N=213)=121.08, p=.00 ; \mathrm{RMSEA}=.07(\mathrm{CI}=.05$ to .09$) ; \mathrm{CFI}=.95 ; \mathrm{SRMR}=.06$

In the second alternative model test (Model D), the recursive model was reversed so that well-being was an exogenous variable, social support satisfaction was a mediator variable, and the attachment dimensions were separate outcome variables. Given that social support satisfaction (and not actual social support) was a variable of interest in the present study, it was possible that emerging adult well-being could be associated with social support satisfaction, which in turn could be associated with attachment security. The fit indices for this model were identical to the recursive model: SB- $\chi^{2}(59, N=213)=101.90, p=.00 ; \mathrm{RMSEA}=.06(\mathrm{CI}=.04$ to .07$) ; \mathrm{CFI}=.97 ; \mathrm{SRMR}=.05$. Importantly, the significance of the indirect effects in this model remained unchanged with respect to Model A. That is, social support satisfaction significantly mediated the association between attachment anxiety and well-being in Model $\mathrm{A}(\beta=-.21, B=$ $.45,95 \% \mathrm{CI}=-.87$ to $-.24, p<.001)$ and the association between well-being and attachment anxiety in Model D $(\beta=-.19, B=-.09,95 \% \mathrm{CI}=-.16$ to $-.04, p<.01)$. Similarly, social support satisfaction did not mediate the association between attachment avoidance and well-being in Model A $(\beta=-.05, B=-.10,95 \% \mathrm{CI}=-.28$ to $.03, p>.05)$ nor the association of well-being predicting attachment avoidance in Model $\mathrm{D}(\beta=-.07, B=-.04,95 \% \mathrm{CI}=-.10$ to $.02, p>.05)$. While this result suggested that multiple plausible explanations exist regarding the relatedness of attachment anxiety, social support satisfaction, and well-being, it also seemed to strengthen the finding that no significant indirect effect existed between attachment avoidance, social support 
satisfaction, and well-being.

\section{Discussion}

The findings of the present study provided mixed support of the theoretical mediation model describing the relations between attachment anxiety, attachment avoidance, social support satisfaction, and well-being among emerging adults experiencing normative life transitions. Specifically, the SEM analyses revealed that social support satisfaction fully mediated the association between attachment anxiety and well-being. However, social support satisfaction did not mediate the association between attachment avoidance and well-being. Finally, alternative model tests provided mixed support for the ordering of variables within the model. That is, while a model that was equivalent in fit supported the nonsignificant indirect effect involving attachment avoidance, it failed to suggest a preferred indirect effect involving attachment anxiety (i.e., well-being predicting attachment anxiety through social support satisfaction was significant in the alternative model test).

These findings collectively suggest that attachment anxiety, but not attachment avoidance, is associated with social support satisfaction. This distinction contrasts existing crosssectional research that has largely found similar relationships to social support across attachment dimensions (e.g., Mallinckrodt \& Wei, 2005). Several differences exist between these studies and the present study, including the use in the present study of emerging adults from a range of academic and non-academic settings. Perhaps the most plausible reason for this discrepancy, though, is that participants in the present sample were experiencing life transition. Recall that the theoretical model was predicated on the idea that emerging adult life transitions are likely sources of distress (e.g., Lee \& Gramotnev, 2007). Periods of distress are theorized to activate secondary attachment strategies (Lopez \& Brennan, 2000), resulting in (a) maladaptive 
interpersonal proximity-seeking among individuals with elevated attachment anxiety and (b) maladaptive interpersonal isolation among individuals with elevated attachment avoidance. If the sample's transition status did, in fact, increase distress levels, it perhaps resulted in a strengthened relation between attachment anxiety and satisfaction with social support and a weakened relation between attachment avoidance and satisfaction with social support on the basis of each dimension's respective secondary attachment strategy. It may be that a measure of actual social support (as opposed to satisfaction) would have yielded more congruent effects. Such a possibility warrants future research.

Moreover, in the structural model analyses, the association between attachment avoidance and well-being remained significant after accounting for social support satisfaction, while the association between attachment anxiety and well-being was fully mediated. This difference was unexpected, and it supported an interpretation that social support satisfaction works differently between each attachment dimension. The hypothesis that social support satisfaction would fully mediate the association between attachment anxiety and well-being was supported. However, the findings suggested that attachment avoidance was negatively associated with well-being independent of social support satisfaction. Further research is needed to identify indirect effects explaining the association between attachment avoidance and well-being among emerging adults in transition.

The present findings elucidate the direct and indirect effects of attachment and social support satisfaction in emerging adult well-being. The majority of existing research in this regard include only negative symptoms as outcome variables (e.g., Kenny \& Sirin, 2006). An implied assumption in such research is that low scores on negative symptom measures are indicative of positive functioning; however, a growing argument in psychological research is that mental 
illness and mental health are separate constructs entirely, not polar ends of the same construct (Keyes, Ryff, \& Shmotkin, 2002). While prior research indicates that attachment security provides a protective factor from negative experiences, the present study provides evidence that attachment security is also associated with well-being.

However, the alternative model testing provided a competing explanation regarding the relatedness of attachment anxiety, social support satisfaction, and well-being compared to that of the theoretical model. While it was hypothesized that attachment anxiety would be indirectly associated with well-being through social support satisfaction, a reversed sequence of associations between these variables also proved to be statistically significant. This alternative explanation suggested that emerging adult well-being could be indirectly associated with attachment anxiety through its association with social support satisfaction. Keren and Mayseless (2013) used a cross-sectional design similar to the present study and found evidence that chosen attachments (e.g., romantic partners) tend to be more secure than unchosen attachments (i.e., family), suggesting that attachment may become more secure in emerging adulthood as individuals increasingly rely on chosen attachments for support. These competing explanations warrant further investigation using longitudinal designs with emerging adult samples.

\section{Limitations}

In interpreting the present study's findings, several limitations warrant consideration.

First, this study relied on a cross-sectional design. While such a design mirrors other prominent attachment and social support research, it limits the ability to make cause-and-effect conclusions about the findings. Second, the sample predominantly was non-Latino white $(83.1 \%)$ and female (72.3\%), and reported full-time enrollment in college immediately after completing high school $(87.3 \%)$. The sample did, however, report a diverse range of present life trajectories (e.g., career 
life), which is important to note considering the aforementioned overreliance on college student samples in other adult research. Nevertheless, the relatively homogenous sample limits the interpretability of the present findings. For example, the nonsignificant indirect effect involving attachment avoidance could be partially due to the fact that attachment avoidance tends to be lower among females (Del Giudice, 2009) and Caucasians (Wei, Russell, Mallinckrodt, \& Zakalik, 2004) compared to males and individuals from certain non-Caucasian groups, respectively. Finally, it should be noted that the study did not use a manipulation check to ensure that participants maintained attentiveness throughout the survey. Manipulation checks are especially useful when survey instructions are complex (e.g., when independent variables are manipulated within the instructions; Oppenheimer, Meyvis, \& Davidenko, 2009); none of the present study variables were predicated on complex instructions. Nevertheless, checking for attentiveness would have provided additional assurances regarding the validity of the data.

\section{Implications for Counseling}

The results of this study indicated that social support satisfaction has a mediating effect on the association between attachment anxiety and well-being among emerging adults experiencing life transition. Social support satisfaction, then, may be a protective factor for wellbeing during transition for individuals with elevated attachment anxiety. Thus, counselors would be wise to assist their emerging adult clients in fostering healthier self-representations. Given that the negative self-representations indicative of attachment anxiety promote maladaptive interpersonal dependence (Lopez \& Brennan, 2000), the development of more positive selfrepresentations could assist emerging adults in optimizing their utilization of the protective qualities of social support. Counselors of emerging adults should be aware of this potential therapeutic roadblock that insecure attachment can create, and they should be prepared to 
intervene to develop corrective attachment experiences in their clients. A promising approach in this regard is for clinicians to utilize the inherent transference of the therapeutic relationship to increase attachment awareness (Daly \& Mallinckrodt, 2009).

The noteworthy magnitude of the association between social support satisfaction and well-being has useful implications for therapy as well. This result underscored the importance of support during potentially distressing life transitions. Support seems to provide a protective factor during these transitions for many qualities of common focus in counseling (Lane, 2015), including environmental mastery, positive relations, purpose in life, self-acceptance, life satisfaction, and a healthy balance between positive and negative affect. These qualities represent important areas of focus when counseling emerging adult clients, especially those in transition.

\section{Implications for Future Research}

The findings of this study make important contributions to what is presently known about emerging adulthood, life transition, attachment, social support satisfaction, and well-being. One important next step is to refine and retest the model in light of the lack of significance between attachment avoidance and social support satisfaction. Based on the aforementioned discussion of this result, it would be useful to devise a study of the relatedness of attachment avoidance and social support while manipulating distress levels. It is also important to compare the fit of these models between transitioning and non-transitioning emerging adults and to test the model using a longitudinal design, which would further validate the present theoretical assertions. Similarly, a longitudinal design would best determine the sequencing of the study variables, which seems warranted given the inconclusive alternative model tests. Finally, the final model should be tested on a more heterogeneous sample with regard to ethnicity and gender. Such efforts would further elucidate our understanding of the psychological impact of emerging adult transitions. 


\section{References}

Anderson, J. C., \& Gerbing, D. W. (1988). Structural equation modeling in practice: A review and recommended two-step approach. Psychological Bulletin, 103(3), 411-423. doi:10.1037//0033-2909.103.3.411

Arnett, J. J. (2004). Emerging adulthood: The winding road from the late teens through the twenties. New York: Oxford University Press.

Bachman, J. G., Johnston, L. D., O’Malley, P., \& Schulenberg, J. (1996). Transitions in drug use during late adolescence and young adulthood. In J. A. Graber, J. Brooks-Gunn, \& A. C. Petersen (Eds.), Transitions through adolescence: Interpersonal domains and context (pp. 111-140). Mahwah, NJ: Erlbaum.

Bowlby, J. (1969/1982). Attachment and loss: Vol. 1. Attachment. New York: Basic Books.

Brennan, K. A., Clark, C. L., \& Shaver, P. R. (1998). Self-report measurement of adult attachment: An integrative overview. In J. A. Simpson \& W. S. Rholes (Eds.), Attachment theory and close relationships (pp. 46-76). New York: Guilford Press.

Buhl, H. M. (2007). Well-being and the child-parent relationship at the transition from university to work life. Journal of Adolescent Research, 22(5), 550-571.

Cohen, P., Kasen, S., Chen, H., Hartmark, C. \& Gordon, K. (2003). Variations in patterns of developmental transitions in the emerging adulthood period. Developmental Psychology, 39(4), 657-669. doi:10.1037/0012-1649.39.4.657

Cohen, S. (2004). Social relationships and health. American Psychologist, 59(8), 676-684. doi:10.1037/0003-066X.59.8.676

Daly, K. D., \& Mallinckrodt, B. (2009). Experienced therapists' approach to psychotherapy for adults with attachment avoidance or attachment anxiety. Journal of Counseling 
Psychology, 56(4), 549-563. doi:10.1037/a0016695

Del Giudice, M. (2009). Sex, attachment, and the development of reproductive strategies.

Behavioral and Brain Sciences, 32, 1-21. doi:10.1017/S0140525X09000016

Diener, E., Emmons, R. A., Larsen, R. J., \& Griffin, S. (1985). The Satisfaction With Life Scale. Journal of Personality Assessment, 49(1), 71-75. doi:10.1207/s15327752jpa4901_13

Ditzen, B., Schmidt, S., Strauss, B., Nater, U. M., Ehlert, U., \& Heinrichs, M. (2008). Adult attachment and social support interact to reduce psychological but not cortisol responses to stress. Journal of Psychosomatic Research, 64, 479-486. doi:10.1016/j.jpsychores.2007.11.011

Fraley, R. C., \& Davis, K. E. (1997). Attachment formation and transfer in young adults' close friendships and romantic relationships. Personal Relationships, 4(2), 131-144. doi:10.1111/j.1475-6811.1997.tb00135.x

Galambos, N. L., Barker, E. T., \& Krahn, H. J. (2006). Depression, self-esteem, and anger in emerging adulthood: Seven-year trajectories. Developmental Psychology, 42(2), 350-365. doi:10.1037/0012-1649.42.2.350

Gore, S., \& Aseltine, R. H., Jr. (2003). Race and ethnic differences in depressed mood following the transition from high school. Journal of Health and Social Behavior, 44(3), 370-389. doi: $10.2307 / 151978$

Hu, L., \& Bentler, P. M. (1999). Cutoff criteria for fit indexes in covariance structure analysis: Conventional criteria versus new alternatives. Structural Equation Modeling: A Multidisciplinary Journal, 6(1), 1-55. doi:10.1080/10705519909540118

Ingram, R. E., \& Gallagher, M. W. (2010). The nature of adult vulnerability: History and definitions. In R. E. Ingram \& J. M. Price (Eds.), Vulnerability to psychopathology: Risks 
across the lifespan (2 ${ }^{\text {nd }}$ ed., pp. 39-56). New York: Guilford Press.

Kenny, M. E., \& Donaldson, G. A. (1991). Contributions of parental attachment and family structure to the social and psychological functioning of first-year college students. Journal of Counseling Psychology, 38(4), 479-486. doi:10.1037/0022-0167.38.4.479

Kenny, M. E., \& Sirin, S. R. (2006). Parental attachment, self-worth, and depressive symptoms among emerging adults. Journal of Counseling \& Development, 84(1), 61-71. doi:10.1002/j.1556-6678.2006.tb00380.x

Keren, E., \& Mayseless, O. (2013). The freedom to choose secure attachment relationships in adulthood. The Journal of Genetic Psychology, 174(3), 271-290.

Keyes, C. L. M., Ryff, C. D., \& Shmotkin, D. (2002). Optimizing well-being: The empirical encounter of two traditions. Journal of Personality and Social Psychology, 82(6), 10071022. doi:10.1037//0022-3514.82.6.1007

Lane, J. A. (2015). Counseling emerging adults in transition: Practical applications of attachment and social support research. The Professional Counselor, 5(1), 30-42.

Lane, J. A. (in press). Attachment, well-being, and college senior concerns about the transition out of college. Journal of College Counseling.

Lee, C., \& Gramotnev, H. (2007). Life transitions and mental health in a national cohort of young Australian women. Developmental Psychology, 43(4), 877-888. doi:10.1037/00121649.43.4.877

Lent, R. W. (2004). Toward a unifying theoretical and practical perspective on well-being and psychological adjustment. Journal of Counseling Psychology, 51(4), 482-509. doi:10.1037/0022-0167.51.4.482

Little, R. J. A. (1988). A test of missing completely at random for multivariate data with missing 
values. Journal of the American Statistical Association, 83(404), 1198-1202.

doi:10.1080/01621459.1988.10478722

Lopez, F. G., \& Brennan, K. A. (2000). Dynamic processes underlying adult attachment organization: Toward an attachment theoretical perspective on the healthy and effective self. Journal of Counseling Psychology, 47, 283-301.

Mallinckrodt, B., Abraham, W. T., Wei, M., Russell, D. W. (2006). Advances in testing the statistical significance of mediation effects. Journal of Counseling Psychology, 53(3), 372-378. doi:10.1037/0022-0167.53.3.372

Mallinckrodt, B., \& Wei, M. (2005). Attachment, social competencies, social support, and psychological distress. Journal of Counseling Psychology, 52(3), 358-367. doi:10.1037/0022-0167.52.3.358

Manago, A. M., Taylor, T., \& Greenfield, P. M. (2012). Me and my 400 friends: The anatomy of college students' Facebook networks, their communication patterns, and well-being. Developmental Psychology, 48(2), 369-380. doi:10.1037/a0026338

Marsh, H. W., Balla, J. R., \& McDonald, R. P. (1988). Goodness-of-fit indexes in confirmatory factor analysis: The effect of sample size. Psychological Bulletin, 103(3), 391-410.

Mortimer, J. T., Zimmer-Gembeck, M. J., Holmes, M., \& Shanahan, M. J. (2002). The process of occupational decision-making: Patterns during the transition to adulthood. Journal of Vocational Behavior, 61, 439-465. doi:10.1006/jvbe.2002.1885

Muthén, L. K., \& Muthén, B. O. (1998-2012). Mplus User's Guide (7 $7^{\text {th }}$ Edition). Los Angeles, CA: Muthén \& Muthén.

Oppenheimer, D. M., Meyvis, T., \& Davidenko, N. (2009). Instructional manipulation checks: Detecting satisficing to increase statistical power. Journal of Experimental Social 
Psychology, 45, 867-872. doi: 10.1016/j.jesp.2009.03.009

Padilla-Walker, L. M., \& Nelson, L. J. (2012). Black hawk down?: Establishing helicopter parenting as a distinct construct from other forms of parental control during emerging adulthood. Journal of Adolescence, 35(5), 1177-1190.

Polach, J. L. (2004). Understanding the experience of college graduates during their first year of employment. Human Resource Development Quarterly, 15(1), 5-23.

Russell, D. W., Kahn, J. H., Spoth, R., \& Altmaier, E. M. (1998). Analyzing data from experimental studies: A latent variable structural equation modeling approach. Journal of Counseling Psychology, 45, 18-29. doi:10.1037/0022-0167.45.1.18

Ryff, C. D. (1989). Happiness is everything, or is it? Explorations on the meaning of psychological well-being. Journal of Personality and Social Psychology, 57(6), 10691081. doi:10.1037/0022-3514.57.6.1069

Sarason, B. R., Pierce, G. R., Shearin, E. N., Sarason, I. G., Waltz, J. A., \& Poppe, L. (1991). Perceived social support and working models of self and actual others. Journal of Personality and Social Psychology, 60(2), 273-287. doi:10.1037/0022-3514.60.2.273

Sarason, I. G., Sarason, B. R., Shearin, E. N., \& Pierce, G. R. (1987). A brief measure of social support: Practical and theoretical implications. Journal of Social and Personal Relationships, 4(4), 497-510. doi:10.1177/0265407587044007

Satorra, A., \& Bentler, P. M. (2001). A scaled difference chi-square test statistic for moment structural analysis. Psychomtrika, 66(4), 507-514. doi:10.1007/BF02296192

Scharf, M., Mayseless, O., \& Kivenson-Baron, I. (2004). Adolescents' attachment representations and developmental tasks in emerging adulthood. Developmental Psychology, 40(3), 430-444. doi:10.1037/0012-1649.40.3.430 
Schlomer, G. L., Bauman, S., \& Card, N. A. (2010). Best practice for missing data management in counseling psychology. Journal of Counseling Psychology, 57, 1-10. doi:0.1037/a0018082

Seiffge-Krenke, I., Persike, M., \& Luyckx, K. (2013). Factors contributing to different agency in work and study: A view on the "Forgotten Half". Emerging Adulthood, 1(4), 283-292.

Shrout, P. E., \& Bolger, N. (2002). Mediation in experimental and non-experimental studies: New procedures and recommendations. Psychological Methods, 7(4), 422-445.

Springer, K. W., \& Hauser, R. M. (2006). An assessment of the construct validity of Ryff's Scales of Psychological Well-Being: Method, mode, and measurement effects. Social Science Research, 35(4), 1080-1102. doi:10.1016/j.ssresearch.2005.07.004

Vogel, D. L., \& Wei, M. (2005). Adult attachment and help-seeking intent: the mediating roles of psychological distress and perceived social support. Journal of Counseling Psychology, 52(3), 347-357. doi:10.1037/0022-0167.52.3.347

Watson, D., Clark, L. A., \& Tellegen, A. (1988). Development and validation of brief measures of positive and negative affect: The PANAS Scales. Journal of Personality and Social Psychology, 54(6), 1063-1070. doi:10.1037/0022-3514.54.6.1063

Wei, M., Russell, D. W., Mallinckrodt, B., \& Vogel, D. L. (2007). The Experiences in Close Relationship Scale (ECR)-Short Form: Reliability, validity, and factor structure. Journal of Personality Assessment, 88, 187-204. doi:10.1080/00223890701268041

Wei, M., Russell, D. W., Mallinckrodt, B., \& Zakalik, R. A. (2004). Cultural equivalence of adult attachment across four ethnic groups: Factor structure, structured means, and associations with negative mood. Journal of Counseling Psychology, 51(4), 408-417. doi:10.1037/0022-0167.51.4.408 
Table 1

Factor Loadings for the Measurement Model

\begin{tabular}{|c|c|c|c|c|}
\hline $\begin{array}{c}\text { Latent variable and } \\
\text { indicator }\end{array}$ & $\begin{array}{l}\text { Unstandardized } \\
\text { factor loading }\end{array}$ & $S E$ & $Z$ & $\begin{array}{l}\text { Standardized } \\
\text { factor loading }\end{array}$ \\
\hline \multicolumn{5}{|l|}{ Attachment anxiety } \\
\hline Parcel 1 & 2.29 & .29 & $7.85^{*}$ & .58 \\
\hline Parcel 2 & 3.74 & .33 & $11.41 *$ & .94 \\
\hline \multicolumn{5}{|l|}{ Attachment avoidance } \\
\hline Parcel 1 & 2.73 & .18 & $14.88^{*}$ & .83 \\
\hline Parcel 2 & 3.95 & .24 & $16.42 *$ & .99 \\
\hline \multicolumn{5}{|l|}{ Social support } \\
\hline Parcel 1 & 2.25 & .20 & $11.31 *$ & .91 \\
\hline Parcel 2 & 2.61 & .21 & $12.20 *$ & .92 \\
\hline \multicolumn{5}{|l|}{ Well-being } \\
\hline Life satisfaction & 5.01 & .35 & $14.40 *$ & .76 \\
\hline Positive affect & 4.61 & .41 & $11.27 *$ & .65 \\
\hline Negative affect & -2.59 & .53 & $-4.89 *$ & -.34 \\
\hline Environmental mastery & 4.61 & .31 & $15.02 *$ & .80 \\
\hline Self acceptance & 6.14 & .32 & $18.99 *$ & .89 \\
\hline Purpose in life & 4.27 & .32 & $13.48 *$ & .74 \\
\hline Positive relations & 4.57 & .33 & $13.92 *$ & .73 \\
\hline
\end{tabular}

Note: $N=213$.

$* p<.001$. 
Table 2

Descriptive Statistics and Intercorrelations among Instrument Scales

\begin{tabular}{|c|c|c|c|c|c|c|c|c|c|c|c|c|}
\hline \multirow[t]{2}{*}{ Variables } & \multicolumn{3}{|c|}{ Descriptives } & \multicolumn{9}{|c|}{ Intercorrelations } \\
\hline & $\alpha$ & $M$ & $S D$ & 1 & 2 & 3 & 4 & 5 & 6 & 7 & 8 & 9 \\
\hline 1. ECR-S Anxiety & .75 & 21.33 & 6.99 & - & & & & & & & & \\
\hline 2. ECR-S Avoidance & .85 & 15.16 & 6.82 & .35 & - & & & & & & & \\
\hline 3. SSQ6 & .90 & 31.21 & 5.09 & -.42 & -.30 & - & & & & & & \\
\hline 4. SWLS & .87 & 24.10 & 6.64 & -.36 & -.30 & .55 & - & & & & & \\
\hline 5. PANAS Positive Affect & .87 & 35.95 & 7.15 & -.28 & -.22 & .37 & .49 & - & & & & \\
\hline 6. PANAS Negative Affect & .85 & 25.58 & 7.58 & .28 & .18 & -.18 & -.34 & $-.07 \dagger$ & - & & & \\
\hline 7. RSPWB Environmental Mastery & .76 & 29.52 & 5.78 & -.33 & -.33 & .43 & .60 & .52 & -.33 & - & & \\
\hline 8. RSPWB Self-Acceptance & .84 & 30.35 & 6.96 & -.39 & -.31 & .47 & .68 & .57 & -.29 & .71 & - & \\
\hline 9. RSPWB Purpose in Life & .77 & 32.96 & 5.87 & -.32 & -.27 & .36 & .46 & .53 & -.21 & .62 & .66 & - \\
\hline 10. RSPWB Positive Relations & .81 & 32.64 & 6.24 & -.31 & -.44 & .51 & .54 & .48 & -.22 & .54 & .65 & .55 \\
\hline
\end{tabular}

Note: $N=213$. ECR-S = Experiences in Close Relationships Scale- Short Form, SSQ6 = Social Support Questionnaire satisfaction scale, SWLS = Satisfaction with Life Scale, PANAS = Positive and Negative Affect Schedule, RSPWB = Ryff Scales of Psychological Well-Being.

$\dagger=$ non-significant correlation. All other correlations significant at the $p<.05$ level or higher. 


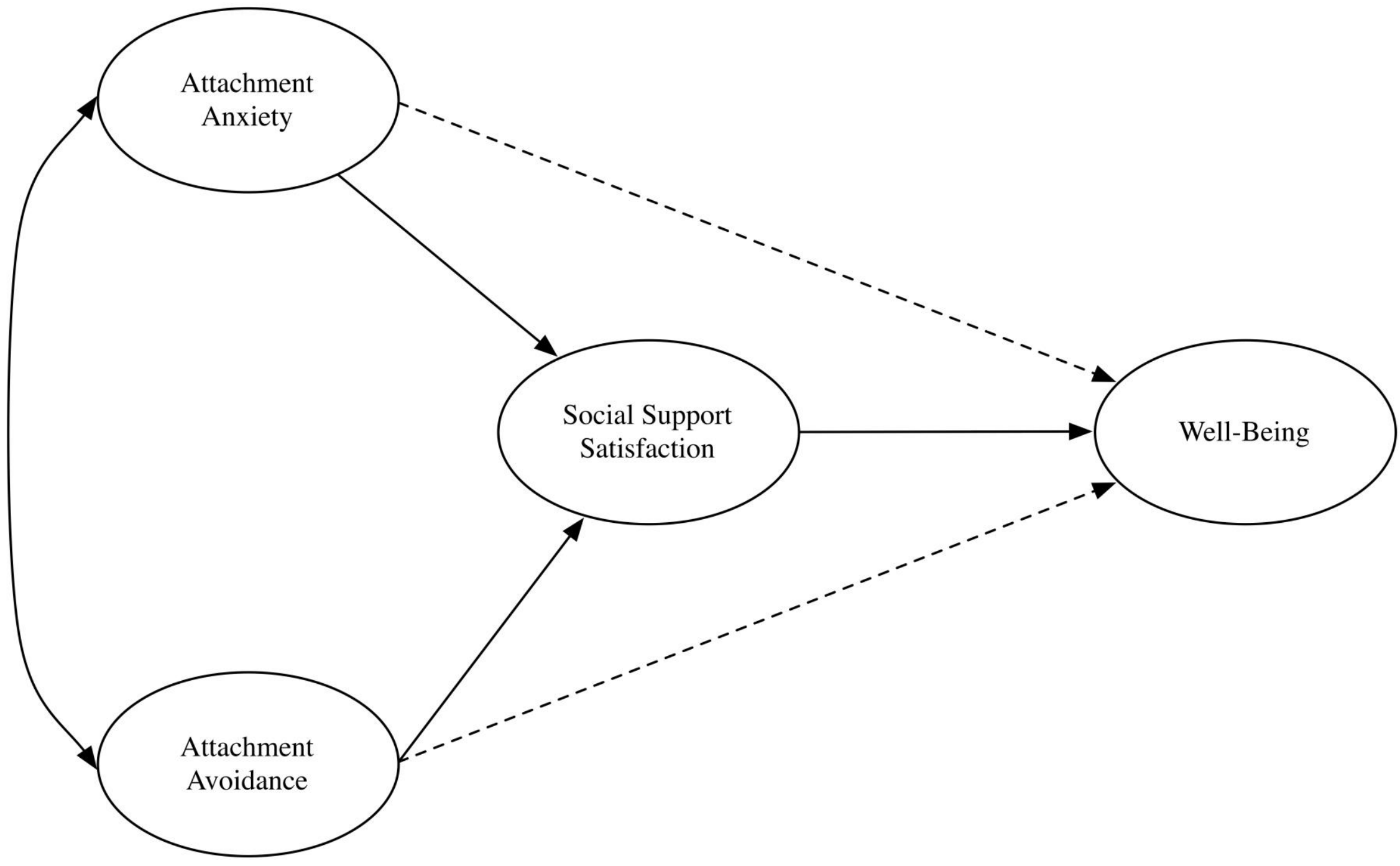

Figure 1. theoretical model depicting relationships among study variables. Dashed lines represent paths that are not hypothesized to be statistically significant. 


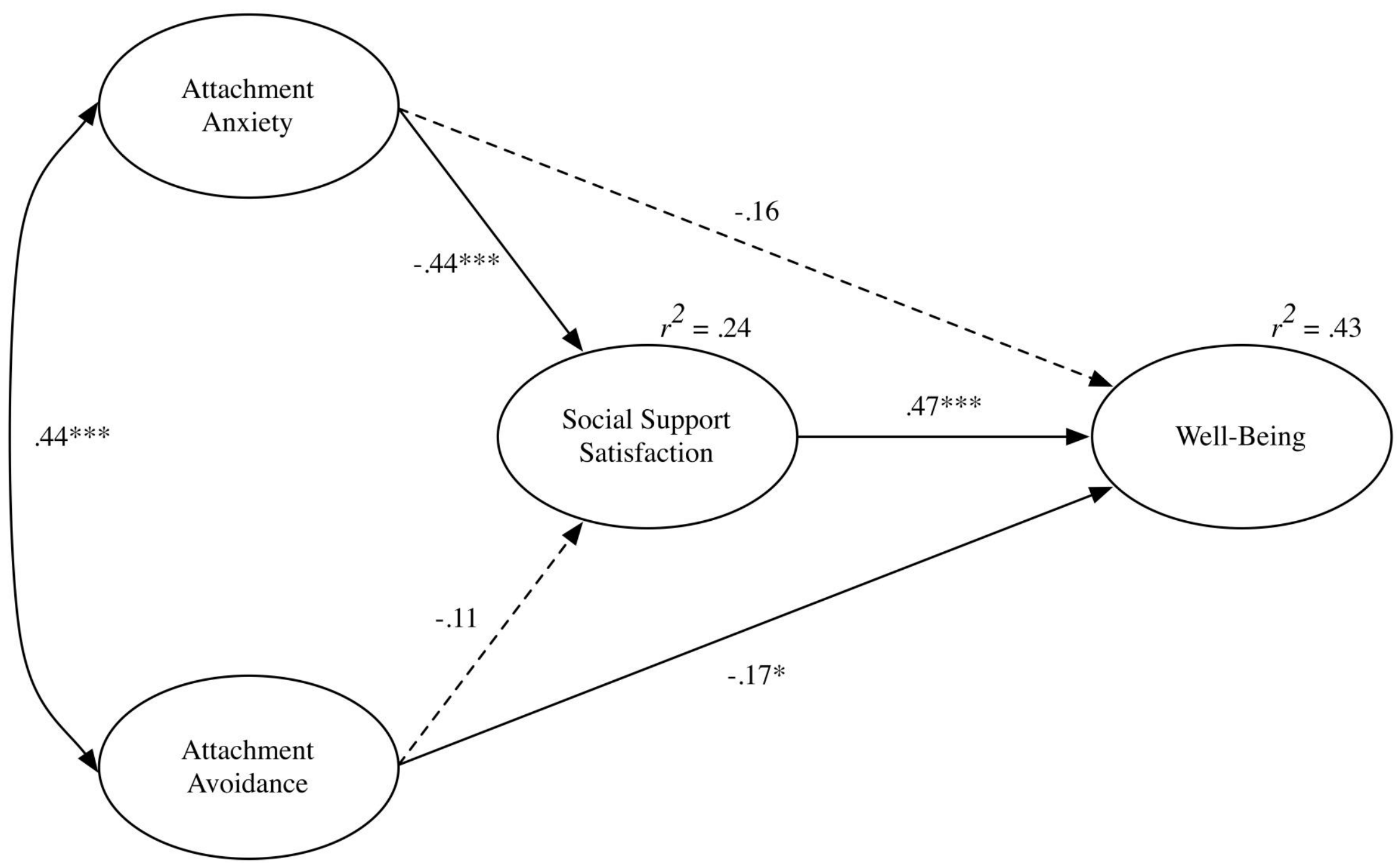

Figure 2. Final structural model. Dashed lines indicate nonsignificant paths. $* p<.05, * * p<.01, * * * p<.001$. 